\title{
昡pubvet
}

https://doi.org/10.31533/pubvet.v15n11a966.1-5

\section{Deformidade flexural em potro}

\author{
Mychell Feitosa Castro de Amorim ${ }^{1 *}$, Paula Bittencourt Vago ${ }^{1 \bullet}$, Marcondes Chaves Gomes ${ }^{2}$, Aline \\ Maia Silva ${ }^{1}$
}

${ }^{1}$ Faculdade Terra Nordeste (FATENE), Rua Coronel Correia, 1119 - Caucaia, Ceará. CEP: 61.600-000. ${ }^{2}$ Hospital Geral Veterinário

*Autor para correspondência, E-mail: mychellfeitosa9@gmail.com.br

Resumo. As deformidades flexurais são caracterizadas pelo desvio da orientação normal do membro, detectadas pela permanente hiperflexão de uma ou mais regiões articulares. $O$ termo deformidade flexural ou tendões contraídos tem sido utilizado tradicionalmente para representar várias deformidades flexoras nos membros. Todavia, o potencial para contração deste tecido é limitado. O defeito primário não está necessariamente no tendão. As deformidades flexurais congênitas devem ser tratadas imediatamente após o seu diagnóstico, com a severidade da deformidade ditando o quão agressivo será o tratamento. Quanto mais novo for o potro, melhor a resposta ao tratamento, devido ao fato de que os tecidos se tornam menos responsivos ao tratamento com o passar do tempo. O presente trabalho teve como objetivo relatar um caso de deformidade flexural em um potro submetido a tratamento conservativo. Foi atendido pelo HGV-Hospital Geral Veterinário, em Aquiraz, um potro, macho, não castrado, com cinco dias de idade, pesando aproximadamente $50 \mathrm{~kg}$, o proprietário relatou que após o nascimento o potro estava com os cascos projetados dorsalmente e com dificuldade de locomoção. Ao exame clínico, constatou-se que o potro apresentava hiperflexão bilateral dos membros torácicos, ocasionando deformidade flexural metacarpofalangeana e interfalangeana. Após o diagnóstico foi instituído tratamento à base de oxitetraciclina e tiocochilcosideo e o uso de talas de PVC. O tratamento conservativo com uso da oxitetraciclina e do tiocolchicosídeo no caso de deformidade flexural no potro do presente relato foi eficiente, revertendo o quadro sem trazer sequelas ao potro.

Palavra-Chave: Potro, deformidade flexural, oxitetraciclina

\section{Flexural deformity in foal}

Abstract. Flexural deformities are characterized by deviation from the normal orientation of the limb, detected by the permanent hyperflexion of one or more joint regions. The term flexural deformity or contracted tendons has traditionally been used to represent various flexor deformities in the limbs. However, the potential for contraction of this tissue is limited. The primary defect is not necessarily in the tendon. Congenital flexural deformities should be treated immediately after diagnosis, with the severity of the deformity dictating how aggressive the treatment will be. The younger the foal, the better the response to treatment, due to the fact that the tissues become less responsive to treatment over time. The present study aimed to report a case of flexural deformity in a foal submitted to conservative treatment. Was attended by HGV-Hospital Geral Veterinário, in Aquiraz, a foal, male, uncastrated, with five days of age, weighing approximately $50 \mathrm{~kg}$, the owner reported that after birth the foal had its hooves projected dorsally and with difficulty in locomotion. On clinical examination, it was found that the foal had bilateral hyperflexion of the thoracic limbs, causing metacarpophalangeal and interphalangeal flexural deformity. After the diagnosis, treatment based on oxytetracycline and thiocochylcoside was instituted and the use of PVC splints. Conservative treatment with the use of oxytetracycline and 
thiocolchicoside in the case of flexural deformity in the foal of the present report was efficient, reversing the condition without causing sequels to the foal.

Key word: Foal, flexural deformity, oxytetracycline

\section{Introdução}

As deformidades flexurais são caracterizadas pelo desvio da orientação normal do membro, detectadas pela permanente hiperflexão de uma ou mais regiões articulares. São mais frequentes nas regiões distais dos membros, sendo as articulações interfalângica distal, metacarpo/metatarsofalangiana e a carpal as mais acometidas, porém outras porções podem ser acometidas (Higgins \& Snyder, 2013).

O termo deformidade flexural ou tendões contraídos tem sido utilizado tradicionalmente para representar várias deformidades flexoras nos membros. Todavia, o potencial para contração deste tecido é limitado. O defeito primário não está necessariamente no tendão (Stashak, 2011). Na deformidade flexural podem estar acometidos tanto os músculos flexor digital superficial e profundo assim como seus respectivos tendões, resultando em graus de severidade variados. Em casos leves de hiperextensão ocorre discreta projeção cranial ou palmar/plantar da articulação metacarpo/metatarsofalangeana, sendo que nestes casos pode ocorrer correção espontânea durante as primeiras semanas de vida devido ao fortalecimento de tônus muscular (Auer \& Stick, 2018).

Alterações neuromusculares, defeitos na formação de elastina e problemas relacionados à aderência das fibras de colágeno podem estar envolvido patogênese (Gaughan, 2017). Existe a hipótese de que a base etiológica da síndrome seja a instabilidade articular associada às malformações ósseas que resultam em contratura muscular compensatória (Stashak, 2011).

Potros recém-nascidos apresentando deformidade em região interfalangeana distal poderão apresentar apoio do membro somente na região das pinças dos cascos. As deformidades em região metacarpo ou metatarsofalangeanas poderão algumas vezes impedir que o animal se mantenha em estação. A região cárpica também comumente apresenta este tipo de alteração. O animal poderá se manter em posição quadrupedal, mas manterá seu peso deslocado para os membros posteriores (Auer \& Stick, 2018).

Segundo McIlwraith (2010), as deformidades flexurais com hiperflexão são classificadas em grau I, quando a parede dorsal do casco não ultrapassa o ângulo de $90^{\circ}$ em relação ao solo e grau II, quando este ângulo é superior a $90^{\circ}$. No grau II também é observado crescimento exagerado dos talões, tendência ao encastelamento e maior desgaste em região de pinça.

As deformidades flexurais congênitas devem ser tratadas imediatamente após o seu diagnóstico, com a severidade da deformidade ditando o quão agressivo será o tratamento. Quanto mais novo for o potro, melhor a resposta ao tratamento, devido ao fato de que os tecidos se tornam menos responsivos ao tratamento com o passar do tempo (Embertson, 1994). O tratamento irá variar de acordo com a localização anatômica envolvida e com a severidade da alteração (Gaughan, 2017).

Desta forma, o presente trabalho teve como objetivo relatar um caso de deformidade flexural em um potro com cinco dias de vida submetido a tratamento conservativo.

\section{Atendimento ao paciete}

Foi atendido pelo HGV-Hospital Geral Veterinário, em Aquiraz, um potro, macho, não castrado, com cinco dias de idade, pesando aproximadamente $50 \mathrm{~kg}$. O proprietário relatou que após o nascimento o potro estava com os cascos emboletados e com dificuldade de locomoção. Ao exame clínico, foi realizada a palpação dos membros afim de indentificar quais estruturas estavam acometidas, constatouse que o potro apresentava hiperflexão bilateral dos membros torácicos, ocasionando deformidade flexural metacarpofalangeana e interfalangeana. Devido à hiperflexão, o potro apresentava dificuldades de locomoção e apoio somente com as pinças dos cascos (Figura 1).

De acordo com os sinais mostrados suspeitou-se de deformidade flexural metacarpofalangeana e interfalangeana. Optou-se por iniciar um tratamento conservativo com o uso de oxitetraciclina e tiocolchicósideo, além de imobilização das articulações metacarpofalangeana e interfalangeana distal. 


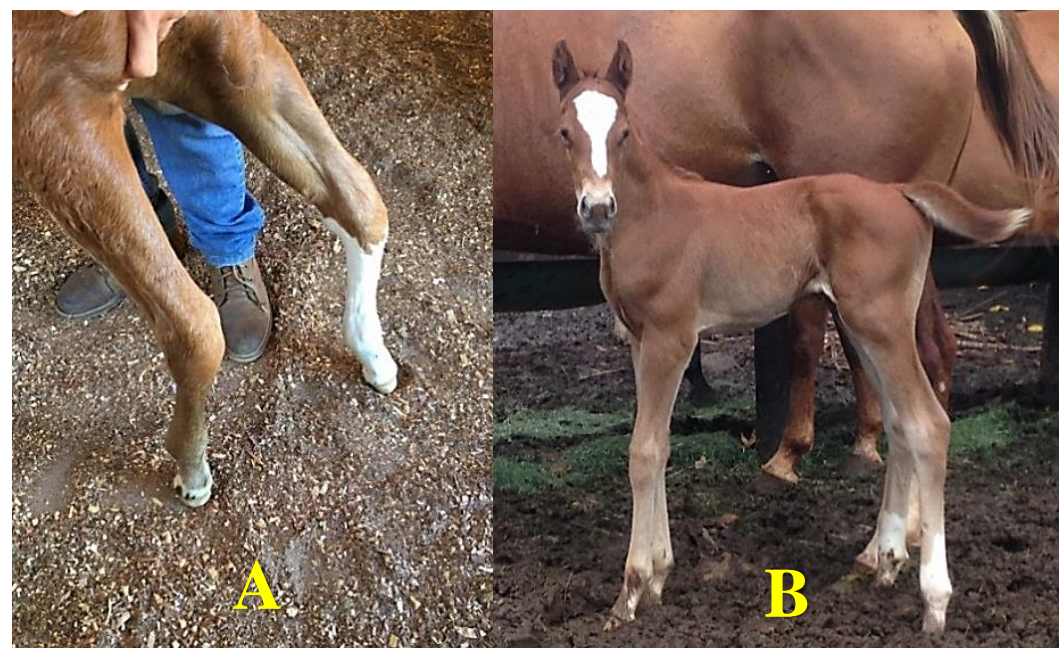

Figura 1. A) Potro com cinco dias de vida, apresentando hiperflexão dos membros torácicos ao exame clínico. B) Potro com idade semelhante, apresentando membros torácicos em posição anatômica.

\section{Resultados e discussão}

Baseado na suspeita clínica, foi instituído tratamento à base de oxitetraciclina na dose de $5 \mathrm{ml}(1$ $\mathrm{ml} / 10 \mathrm{~kg}$ ), a cada quatro dias, por via intramuscular (IM), totalizando três aplicações; tiocolchicósido, um comprimido por dia (4 mg), por via oral (VO), durante dez dias.

Foram utilizadas talas de policloreto de vinila, acolchoadas com algodão em ambos os membros torácicos, as talas foram colocadas a partir da articulação cárpica e se estendendo até a articulação interfalangeana distal com o intuito de manter a posição anatômica dos membros e forçar a hiperextensão (Figura 2).

As deformidades flexurais congênitas em potros apresentam uma rápida evolução, devido ao crescimento acelerado e fatores genéticos, tornando visíveis as alterações de conformação e aprumos, dificultando a movimentação do potro. A idade do potro torna-se fator primordial para obter resultados satisfatórios no tratamento, visto que, devido ao crescimento acelerado da massa óssea, as estruturas adjacentes como tendões e ligamentos não acompanham o crescimento, tornando-se hiperextendidas ou hiperflexionadas.

Em concordância com Auer \& Stick (2018), o diagnóstico das deformidades flexurais congênitas deve ser baseado nas manifestações clínicas do animal. O exame físico de rotina neste tipo de alteração é voltado para o posicionamento do animal quando em posição quadrupedal, e na capacidade de extensão e flexão da articulação envolvida. Foi realizado no exame físico a palpação dos membros afetados com o potro em estação, afim de identificar quais estruturas estavam acometidas conforme citado por Higgins \& Snyder (2013).

Quando diagnosticado precocemente em potros jovens, as deformidades flexurais podem ser revertidas com tratamento conservativo. Considerando que o esqueleto do neonato se encontra na fase inicial de vida, estando em processo de crescimento e sendo passível á remodelações (Gaughan, 2017). As alterações apresentadas pelo potro do caso foram características e de rápida evolução, sendo visível a hiperflexão dos tendões flexores, projetando o boleto dorsalmente (emboletado) e o apoio com as pinças dos cascos conforme citado por McIlwraith (2010).

$\mathrm{O}$ tratamento precoce com medicamentos à base de tetraciclina e oxitetraclina têm demonstrado resultados satisfatórios com a recuperação total dos animais, após uma única dose ou mais. $\mathrm{O}$ uso de oxitetraciclina (2-3 mg/kg) é recomendado em potros com poucos dias de vida e tem-se mostrado eficaz no tratamento de deformidades flexurais logo nas primeiras aplicações. Estudos afirmam que a oxitetraciclina é capaz de quelar os íons de cálcio livres e prevenir o influxo do mesmo nas fibras musculares, induzindo o relaxamento muscular (Auer \& Stick, 2018; Embertson, 1994).

Um estudo in vitro mostrou que a oxitetraciclina induziu uma inibição dependente da dose da contração do gel de colágeno pelos miofibroblastos em eqüinos (Lokai \& Meyer, 1985). A 
oxitetraciclina também induziu uma diminuição dependente da dose na metaloproteinase da matriz 1 Expressão de mRNA (MMP-1) por miofibroblastos eqüinos. Os resultados deste estudo indicam que a oxitetraciclina inibe a estrutura tracional das fibrilas de colágeno por miofibroblastos de equinos através de um mecanismo mediado por MMP-1. A expressão do mRNA da MMP-1 durante esse período pode afetar o processo de remodelação e tornar o tecido em desenvolvimento mais suscetível à fluência. Esse aumento da suscetibilidade do ligamento e dos tendões à fluência pode explicar o relaxamento dessa estrutura em condições clinicamente normais em potros e potros com tendões contraídos na administração de oxitetraciclina. O desenvolvimento de ligamentos e tendões se tornam mais suscetíveis ao alongamento durante a carga normal, o que resulta em correção da deformidade em 24 a 48 horas (Arnoczky et al., 2004).

Segundo Thomassian (2005), a oxitetraciclina deve ser usada pela via intravenosa, diluída em solução fisiológica em dose única, podendo ser repetida após $24 \mathrm{~h}$. No presente caso, a oxitetraciclina foi usada pela via intramuscular em doses múltiplas, repetidas a cada 96 horas, totalizadas três doses, apresentando resultados satisfatórios pela via intramuscular. De acordo com Gaughan (2017) complicações como diarreia, colite, insuficiência renal não foram observadas neste caso.

As talas de pvc foram empregadas para ajudar a manter o potro em estação e para induzir a extensão forçada da articulação. As talas eram ajustadas diariamente de acordo com a evolução do caso, ficando por vinte dias seguidos para que as articulações podessem permanecer em sua posição anatômica, não havendo lesões compressivas nas articulações. Corrêa \& Zoppa (2007) sugerem o uso por 6 horas seguidas e de remoção por seis horas e assim sucessivamente para evitar possíveis lesões, mas nesse modelo torna-se inviável o seu emprego.

$\mathrm{O}$ uso de relaxantes musculares auxilia na redução da contratura e diminuem o desconforto e a dor causado pela hiperflexão das estruturas. O tiocolchicosídeo possui uma afinidade seletiva agonista pelos receptores GABA (ácido gama-aminobutírico), assim como propriedades agonistas glicinérgicas, que promovem atenuação ou supressão das contrações musculares de etiologia central. Por ser de ação central e específica em recepetores inibitórios o tiocolchicosídeo auxilia no relaxamento múscular sem causar outros efeitos como traquilização e sedação, sendo seu uso seguro para este caso. Diminui a resistência passiva do músculo estriado na hipertonia espástica e reduz ou suprime a contratura residual. Por outro lado, este medicamento não possui influência sobre o sistema cardiovascular e na motilidade voluntária, não provoca paralisia, evitando assim o risco respiratório (BLAU, 2014).

Após dez dias de tratamento conservativo, o animal demonstrou aprumos normais e sem sequelas em decorrência da terapêutica e imobilização (igura 3).

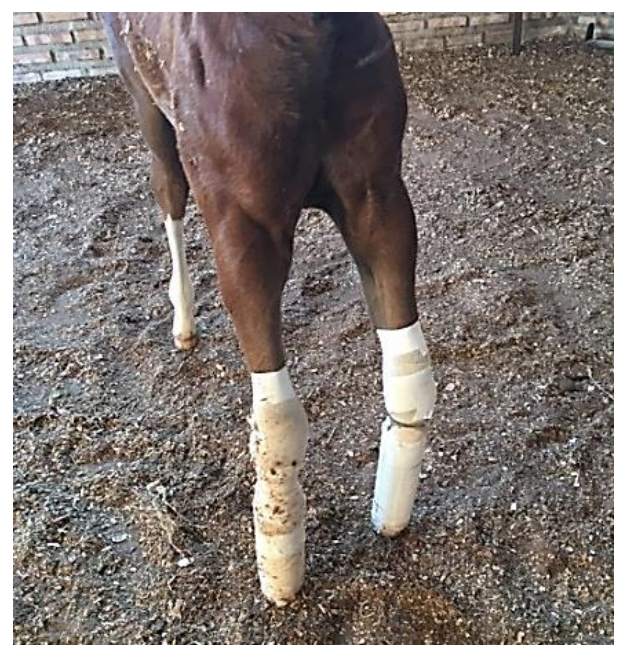

Figura 2. Potro com cinco dias de vida, com hiperflexão dos membros torácicos, com talas de PVC acolchoadas.

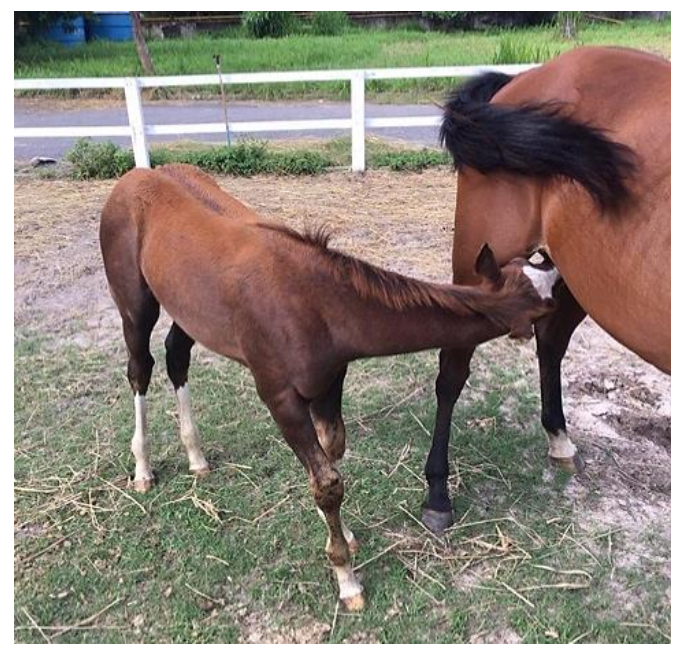

Figura 3. Potro apresentando articulações normais após dez dias de tratamento conservativo.

\section{Conclusões}

O tratamento conservativo com uso da oxitetraciclina, tiocolchicosídeo e imobilização dos membros 
torácicos no caso de deformidade flexural no potro do presente relato foi eficiente, revertendo o quadro sem trazer sequelas ao potro.

\section{Referências bibliográficas}

Arnoczky, S. P., Lavagnino, M., Gardner, K. L., Tian, T., Vaupel, Z. M., \& Stick, J. A. (2004). In vitro effects of oxytetracycline on matrix metalloproteinase- 1 mRNA expression and on collagen gel contraction by cultured myofibroblasts obtained from the accessory ligament of foals. American Journal of Veterinary Research, 65(4), 491-496. https://doi.org/10.2460/ajvr.2004.65.491.

Auer, J. A., \& Stick, J. A. (2018). Equine surgery-E-Book. Elsevier Health Sciences.

Blau Farmacêutica S.A. 2014. Tiocolchicosídeo - disponível em http:www.anvisaa.gov.br/datavisa/fila_bula/frmVvisualizarBulla.asp?pNuTransacao $=1953455201$ \&pldAnexo, acesso em 28-04-2020.

Corrêa, R. R., \& Zoppa, A. L. V. (2007). Deformidades flexurais em eqüinos: revisão bibliográfica. Ensaios e Ciência, 5(5), 37-43.

Embertson, R. M. (1994). Congenital abnormalities of tendons and ligaments. Veterinary Clinics of North America: Equine Practice, 10(2), 351-364. https://doi.org/10.1016/S0749-0739(17)30360-7.

Gaughan, E. M. (2017). Flexural limb deformities of the carpus and fetlock in foals. Veterinary Clinics of North America - Equine Practice, 33, 331-342. https://doi.org/10.1016/j.cveq.2017.03.004.

Higgins, A. J., \& Snyder, J. R. (2013). The equine manual E-Book. Elsevier Health Sciences.

Lokai, M. D., \& Meyer, R. J. (1985). Preliminary observations on oxytetracycline treatment of congenital flexural deformities in foals. Modern Veterinary Practice, 66, 237-239.

McIlwraith, C. W. (2010). Recent advances in diagnosis of equine joint disease. Proceedings of the 17th Kentucky Equine Research Nutrition Conference. Kentucky Equine Research, 23-33.

Stashak, T. S. (2011). Claudicação em eqüinos segundo Adams. Editora Roca.

Thomassian, A. (2005). Enfermidades dos cavalos. Livraria Varela.

Histórico do artigo:

Recebido: 4 de julho de 2021

Aprovado: 7 de agosto de 2021
Licenciamento: Este artigo é publicado na modalidade Acesso Aberto sob a licença Creative Commons Atribuição 4.0 (CC-BY 4.0), a qual permite uso irrestrito, distribuição, reprodução em qualquer meio, desde que o autor e a fonte sejam devidamente creditados. 